\title{
Temperature Effects on Gas Sensing Properties of Electrodeposited Chlorine Doped and Undoped n-Type Cuprous Oxide Thin Films
}

\author{
Nayana Bandara ${ }^{1,2}$, Charith Jayathilaka, ${ }^{1,3}$, Dhammika Dissanayaka ${ }^{4}$, Sumedha Jayanetti1 \\ ${ }^{1}$ Department of Physics, University of Colombo, Colombo, Sri Lanka \\ ${ }^{2}$ Department of Physics, Open University of Sri Lanka, Nawala, Sri Lanka \\ ${ }^{3}$ Department of Physics, University of Kelaniya, Kelaniya, Sri Lanka \\ ${ }^{4}$ Department of Chemistry, University of Colombo, Colombo, Sri Lanka \\ Email: sumedhajayanetti@gmail.com
}

Received 30 May 2014; revised 30 June 2014; accepted 31 July 2014

Copyright (C) 2014 by authors and Scientific Research Publishing Inc.

This work is licensed under the Creative Commons Attribution International License (CC BY). http://creativecommons.org/licenses/by/4.0/

c) (i) Open Access

\section{Abstract}

As one of the most widely used domestic fuels, the detection of possible leakages of Liquefied Petroleum (LP) gas from production plants, from cylinders during their storage, transport and usage is of utmost importance. This article discusses a study of the response of undoped and chlorine doped electrodeposited n-type Cuprous Oxide $\left(\mathrm{Cu}_{2} \mathrm{O}\right)$ films to of $\mathrm{LP}$ gas. Undoped n-type $\mathrm{Cu}_{2} \mathrm{O}$ films were fabricated in an electrolyte bath containing a solution of sodium acetate and cupric acetate whereas n-type chlorine doped $\mathrm{Cu}_{2} \mathrm{O}$ thin films were prepared by adding a $0.02 \mathrm{M}$ cuprous chloride $\left(\mathrm{CuCl}_{2}\right)$ into an electrolyte solution containing lactic acid, cupric sulfate and sodium hydroxide. The n-type conductivity of the deposited films was determined using spectral response measurements. The structural and morphological properties of the fabricated films were monitored using X-ray diffraction (XRD) and Scanning Electron Microscopy (SEM). Due to doping, the overall conductivity of the chlorine doped n-type $\mathrm{Cu}_{2} \mathrm{O}$ films increased by several orders of magnitude. The temperature dependent gas responses of both the undoped and chlorine doped $\mathrm{n}$-type $\mathrm{Cu}_{2} \mathrm{O}$ thin films to the LP gas was monitored by measuring the electrical resistance (R), and using the contact probe method at a constant gas flow rate of $0.005 \mathrm{ml} / \mathrm{s}$. Upon exposure to gases, both doped and undoped films showed a good response to the gas by increasing/decreasing the electrical resistance by $\Delta R$. The undoped n-type $\mathrm{Cu}_{2} \mathrm{O}$ thin films showed a negative response $(\Delta R<0)$ at all temperatures resulting in a maximum response around $85^{\circ} \mathrm{C}$. However, the chlorine doped $\mathrm{n}$-type $\mathrm{Cu}_{2} \mathrm{O}$ thin films initially showed a positive response $(\Delta R>0)$ to the LP gas which then reversed its sign to give a negative response which peaked at $52^{\circ} \mathrm{C}$. The positive response shown by the chlorine doped $\mathrm{Cu}_{2} \mathrm{O}$ films vanished completely at $42^{\circ} \mathrm{C}$. 


\title{
Keywords
}

\author{
Liquefied Petroleum Gas, Electrodeposition, $\mathrm{Cu}_{2} \mathrm{O}$ Thin Films, Chlorine Doped, Undoped, Gas \\ Response
}

\section{Introduction}

Environmentally hazardous gases are being released continuously to the atmosphere due to industrialization, increased human activities and the natural processes that take place as a result of drastic changes in the environment. Therefore, monitoring of environment has been of extreme importance for the safety and well-being of human and animal life and nature in general. Consequently, gas sensing has become an important area of research that leads to the development of highly responsive gas sensing devices capable of detecting minute amounts of gases of different types. One such gas that requires monitoring in the context of developing countries is the highly inflammable Liquefied Petroleum (LP) gas which is being used very widely as a domestic fuel. At most times leakage of LP gas from production plants or from cylinders occur during their storage, transport and usage. These leakages at most times can be found from the odor of the gas, however, by then a significant amount of gases may have leaked out to the surroundings. Gas sensor devices enable the early detection of such leakages thus preventing accidents and wastage while helping maintain a safer and cleaner environment.

With the pioneering work reported in 1962 by Seiyema et al. [1], much technological effort has been made in the field of gas sensing aiming towards improvement of the gas response, selectivity, stability and feasibility for practical use. A principal mechanism employed in gas sensing is the monitoring of the electrical resistance of the sensor material upon its exposure to a particular gas of low concentration. Among the many sensor materials available, use of polycrystalline oxide semiconductor thin films as sensing materials is rapidly expanding. Extensive studies have been made on oxide semiconductors such as $\mathrm{SnO}_{2}, \mathrm{ZnO}$ and $\mathrm{WO}_{3}$, for their gas sensing applications for various types of gases [2] [3]. Recently, there have been a few studies on the use of p-type $\mathrm{Cu}_{2} \mathrm{O}$ thin films as a potential gas sensing material, Alahapitiya et al. [4] have used thermally oxidized p-type $\mathrm{Cu}_{2} \mathrm{O}$ for methane sensing. Shishyano et al. [5] have used electrodeposited p-type $\mathrm{Cu}_{2} \mathrm{O}$ for $\mathrm{NO}_{2}$ gas sensing for $\mathrm{LP}$ gas sensing. Dhawale et al. [6] have explored the possibility of using electron beam irradiated chemically deposited $\mathrm{TiO}_{2}$ thin films. Shukla et al. [7] have reported thesynthesis of tin oxide thick films and their applications in LP gas sening at room temperature.

It has been known that the electrodeposition can be used to fabricate $\mathrm{Cu}_{2} \mathrm{O}$ thin films with both n-type and p-type conductivities [8]. Thus the ability to control the conductivity type, the surface morphology etc. coupled with the ease and associated low cost of fabrication make electrodeposited $\mathrm{Cu}_{2} \mathrm{O}$ thin films a suitable candidate for gas sensing applications. The inherent high resistivity associated with the elctrodeposited $\mathrm{Cu}_{2} \mathrm{O}$ thin films has been considered a drawback that can be addressed using suitable doping methods for related device applications. For example, chlorine doping during the elctrodeposition has lowered the resistivity of $\mathrm{Cu}_{2} \mathrm{O}$ thin films significantly [9]. This paper reports the use of electrodeposited chlorine doped n-type $\mathrm{Cu}_{2} \mathrm{O}$ thin films for monitoring LP gas while making a comparison with the previously reported LP gas sensing behavior of undoped $\mathrm{Cu}_{2} \mathrm{O}$ thin films [10]. The temperature dependent variation of the gas sensing sensitivity is discussed including the reaction mechanisms that cause the observed behaviour.

\section{Experimental}

Both undoped and chlorine doped n-type $\mathrm{Cu}_{2} \mathrm{O}$ thin films were deposited on Ti substrates, a process that has been well established in the research group [9]. Prior to the deposition, the substrates were cleaned thoroughly with detergent, dilute nitric acid, in an acetone bath, and lastly with distilled water. The undoped $\mathrm{Cu}_{2} \mathrm{O}$ thin films were potentiostatically electrodeposited in a three-electrode electrochemical cell that contained aqueous solutions of $0.1 \mathrm{M}$ sodium acetate and $0.01 \mathrm{M}$ cupric acetate and hence termed as an acetate bath. Deposition was carried out for duration of 45 minutes at $60^{\circ} \mathrm{C}$ underpotentiostatic condition of a $-200 \mathrm{mV}$ [9]. However, difficulties were encountered when chlorine doping was attempted using an acetate bath due to precipitation. Doping was therefore accomplished in an electrolytic bath containing aqueous solutions of $3 \mathrm{M}$ lactic acid, 0.45 $\mathrm{M}$ cupric sulfate, and $4 \mathrm{M}$ sodium hydroxide. Sodium hydroxide was used to adjust the $\mathrm{pH}$ of the electrolyte 
around 9.5. A solution of $\mathrm{CuCl}_{2}$ was used as the chlorine precursor by varying its concentration. Resistivity measurements of the resulting $\mathrm{Cu}_{2} \mathrm{O}$ thin films showed that initially the resistance to drop drastically and then gradually beyond a concentration of $0.02 \mathrm{M} \mathrm{CuCl}_{2}$. Thus for gas sensing measurements, $\mathrm{Cu}_{2} \mathrm{O}$ films chlorine doped using a $0.02 \mathrm{M} \mathrm{CuCl}_{2}$ solution was used. The deposition was carried out for a period of 45 minutes, at a constant temperature of $60^{\circ} \mathrm{C}$, under potentiostatic conditions of $-275 \mathrm{mV}$. The n-type conductivity of the deposited films was verified using the spectral response measurements [9]. The surface morphological and structural characterization of the films was determined using SEM (Philips XL40) and XRD (SHIMADZU SSX-550) analysis.

A film sample was then enclosed in a gas sensing chamber made of stainless steel. Chamber contained two compartments; the top through which the gas was flown and the bottom where the heating element was housed. In order to measure the electrical resistance, contact probes were fixed on to the surface of the film sample which was placed on an asbestos heating platform. Externally, the probes were connected to a multimeter, which in turn was connected to a computer data logger (Figure 1).

All the measurements were made under atmospheric conditions by using a flow through technique. While maintaining a constant gas flow rate of $0.005 \mathrm{ml} / \mathrm{s}$, films were exposed to LP gas for approximately $30-40 \mathrm{~s}$. and then the gas flow was stopped. The sensing temperature was varied between $30^{\circ} \mathrm{C}$ and $100^{\circ} \mathrm{C}$ while monitoring the temperature with a thermocouple (type $\mathrm{K}$ ) which was in contact with surface area of the substrate which was not covered by the $\mathrm{Cu}_{2} \mathrm{O}$ film. The temperature was controlled using a thermostat with a temperature controller. The electrical resistivity measurements were made using computer interfaced a Keithley 2100 digital multimeter. The measurements were taken over a period of approximately $120 \mathrm{~s}$ after the gas was sent in to the chamber and repeated when the temperatures were brought down to the room temperature. This procedure was repeated at different temperatures in order to determine the temperature that corresponds to the maximum gas sensitivity.

\section{Results and Discussion}

\subsection{Structure and Morphology}

\subsubsection{X-Ray Diffraction (XRD)}

Figure 2 shows the XRD patterns of the undoped and chlorine doped $\mathrm{Cu}_{2} \mathrm{O}$ thin films. It can be seen that both doped and undoped $\mathrm{Cu}_{2} \mathrm{O}$ thin films show single phase, polycrystalline characteristics. It can be seen from spectrum B in Figure 2, that the undoped $\mathrm{Cu}_{2} \mathrm{O}$ films show a preferred orientation resulting in a stronger (220) reflection. However, doping has caused the preferred orientation to change to produce a stronger (200) reflection in the chlorine doped $\mathrm{Cu}_{2} \mathrm{O}$ film samples.

\subsubsection{Scanning Electron Microscopy}

Figure 3(a) and Figure 3(b) show the SEM pictures of electrodeposited undoped and chlorine doped $\mathrm{Cu}_{2} \mathrm{O}$

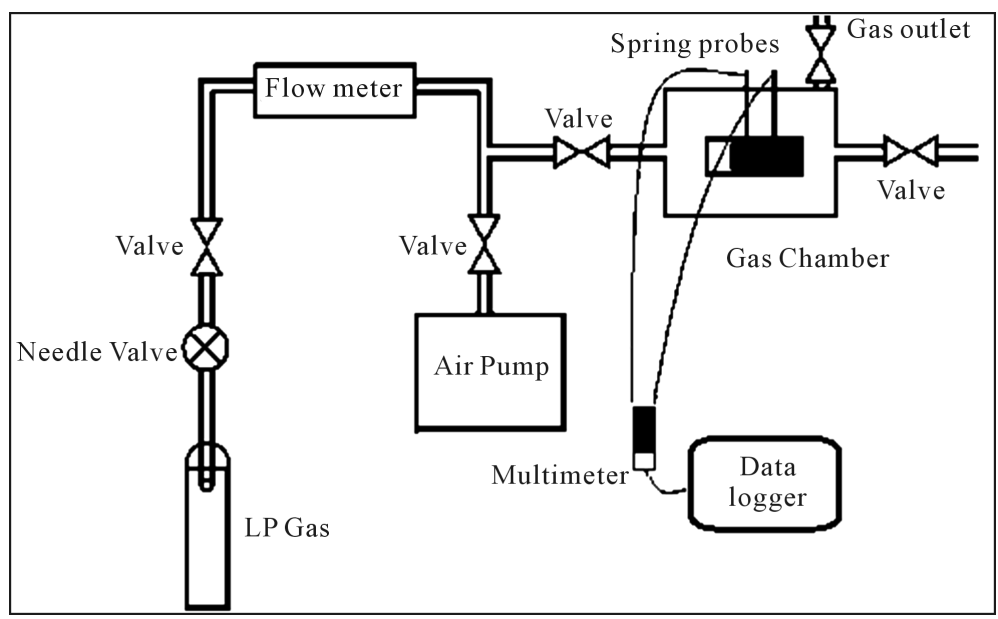

Figure 1. Block diagram of gas sensing setup. 


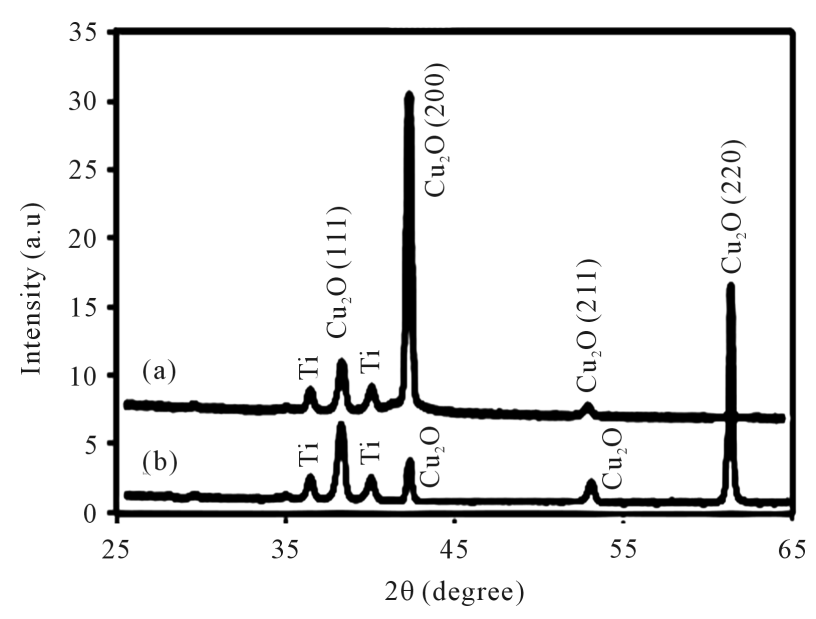

Figure 2. X-ray diffraction spectra of (a) chlorine doped $\mathrm{Cu}_{2} \mathrm{O}$ thin film and (b) undoped $\mathrm{Cu}_{2} \mathrm{O}$ thin film.

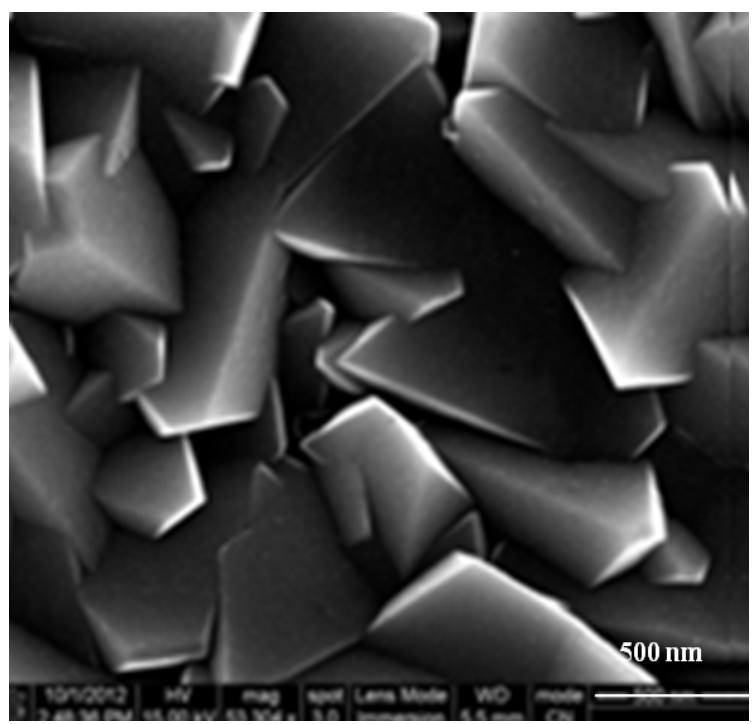

(a)

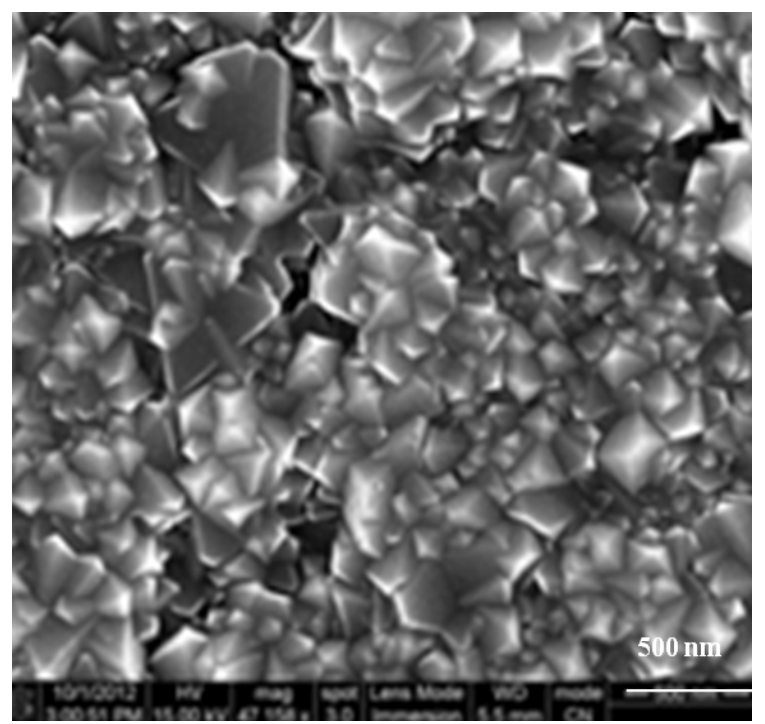

(b)

Figure 3. SEM pictures of (a) undoped $\mathrm{Cu}_{2} \mathrm{O}$ thin film deposited on Ti substrate and (b) chlorine doped $\mathrm{Cu}_{2} \mathrm{O}$ thin film deposited on Ti substrate with a $0.02 \mathrm{M} \mathrm{CuCl}_{2}$ added to the electrolyte bath.

samples indicating that both films have uniform polycrystalline coverage. However, effect of doping has caused the average polycrystalline grain size to reduce towards nanoscale compared to that of the undoped $\mathrm{Cu}_{2} \mathrm{O}$ thin films in which the average grain size is in the micro scale. Through SEM measurements, it was found that the average polycrystalline grain size of chlorine doped $\mathrm{Cu}_{2} \mathrm{O}$ thin films showed a concentration dependence on $\mathrm{CuCl}_{2}$. It was observed that the increased $\mathrm{CuCl}_{2}$ concentration caused the average grain size to reduce gradually providing a larger effective surface area to interact with the gas molecules [11].

\subsubsection{Resistivity Measurements}

Figure 4 shows the resistivity measurements taken of the chlorine doped $\mathrm{Cu}_{2} \mathrm{O}$ samples in which the $\mathrm{CuCl}_{2}$ precursor concentration in the electrolyte was varied during the deposition of the films. It can be seen that initially, the resistivity of the films reduces from $\mathrm{M} \Omega \mathrm{cm}$ range down to $\mathrm{k} \Omega \mathrm{cm}$ range when the $\mathrm{CuCl}_{2}$ precursor concentration in the electrolyte was $0.02 \mathrm{M}$. Further increase in the concentration causes the resistivity to reduce gradually through the $\mathrm{k} \Omega \mathrm{cm}$ range.

This decrease in the resistivity was quite significant when compared to the resistivity of undoped $\mathrm{Cu}_{2} \mathrm{O}$ thin 


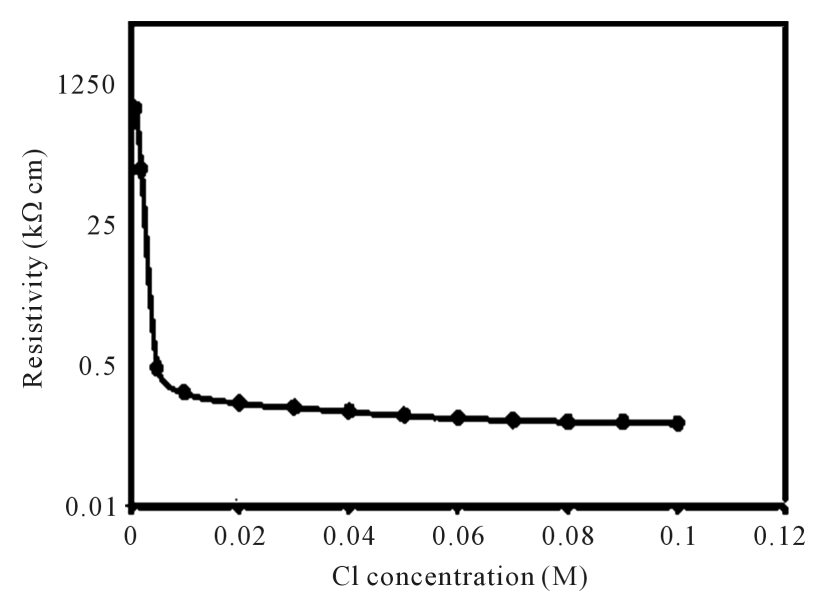

Figure 4. Variation of resistivity of chlorine doped $\mathrm{Cu}_{2} \mathrm{O}$ thin films with $\mathrm{CuCl}_{2}$ concentration in the electrolyte solution maintained at $\mathrm{pH} 9.5$ and temperature $60^{\circ} \mathrm{C}$.

films fabricated electrochemically using the acetate bath which produced $\mathrm{Cu}_{2} \mathrm{O}$ thin films in which the resistivity was larger by over 5 orders of magnitude than the chlorine doped $\mathrm{Cu}_{2} \mathrm{O}$ thin films obtained with the $0.02 \mathrm{M}$ $\mathrm{CuCl}_{2}$ precursor concentration in the electrolyte in the lactate bath.

\subsection{Gas Sensing Properties}

As mentioned above, the gas sensing properties were measured by monitoring the resistance of the $\mathrm{Cu}_{2} \mathrm{O}$ thin films upon exposure to LP gas and its stoppage after a certain period. The response to the gases are represented as resistance vs. time curves and the magnitude of sensitivity vs. time curves where the magnitude of sensitivity is termed as

$$
\text { Sensitivity, } S=\left|\frac{R_{\mathrm{LPG}}-R_{\mathrm{air}}}{R_{\mathrm{air}}}\right|
$$

Here $R_{\mathrm{LPG}}$ is the resistance of the film upon exposure to LP gas and $R_{\mathrm{air}}$ is the resistance of the film when it is under normal atmospheric conditions.

\section{Response at Low Temperatures}

Figure 5(a) shows the variation of resistance of undoped $\mathrm{Cu}_{2} \mathrm{O}$ films as a function of time around room temperature. When the undoped $\mathrm{Cu}_{2} \mathrm{O}$ films were exposed to the $\mathrm{LP}$ gas, films showed a negative response, i.e. the resistance of the film decreased with the exposure time and gradually recovered to its initial value under the normal atmospheric conditions when the gas flow was stopped [10]. In a magnitude of sensitivity vs. time graph, this behavior is depicted by a single response peak as shown in the Figure 5(b).

This behavior can be well understood in terms of the mechanism given by Shukla [7] on LP gas sensing behavior of $\mathrm{SnO}_{2}$ thin films. Under atmospheric conditions, the oxygen adsorbed on the surface of the n-type $\mathrm{Cu}_{2} \mathrm{O}$ thin film extracts electrons from its conduction band to form $\mathrm{O}_{2}^{-}$on the film surface causing the film to be at a higher equilibrium resistance initially. Once the LP gas is sent into the chamber, it reacts with the chemisorbed oxygen removing them from the surface giving the electrons back to the conduction band of the $\mathrm{Cu}_{2} \mathrm{O}$ film as shown by the Equation (2).

$$
2 \mathrm{C}_{\mathrm{n}} \mathrm{H}_{2 \mathrm{n}+2}(\mathrm{ad})+\mathrm{O}_{2}^{-}(\mathrm{ad}) \rightarrow 2 \mathrm{C}_{\mathrm{n}} \mathrm{H}_{2 \mathrm{n}+1}-\mathrm{O}+\mathrm{H}_{2} \mathrm{O}+2 \mathrm{e}^{-}
$$

This reduces the resistance of the film until the LP gas flow in to the chamber is stopped. The stoppage of the gas flow causes atmospheric oxygen to gradually adsorb on the $\mathrm{Cu}_{2} \mathrm{O}$ film once again allowing the resistance to recover back to its value under atmospheric conditions.

In contrast, upon exposure to LP gas, the resistance of the chlorine doped $\mathrm{Cu}_{2} \mathrm{O}$ films increased $\left(R_{\mathrm{LPG}}>R_{\mathrm{air}}\right)$ initially showing a positive response and then showed a negative response $\left(R_{\mathrm{LPG}}<R_{\mathrm{arr}}\right)$ as in the case of undoped 


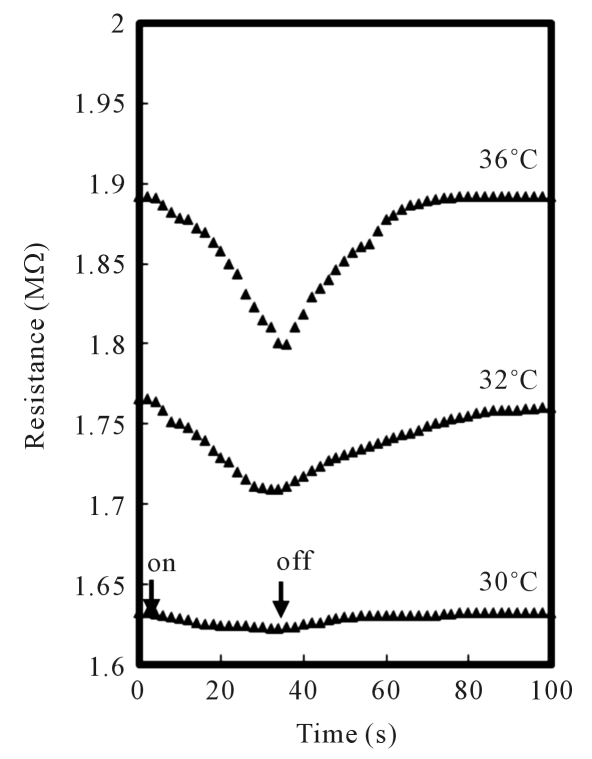

(a)

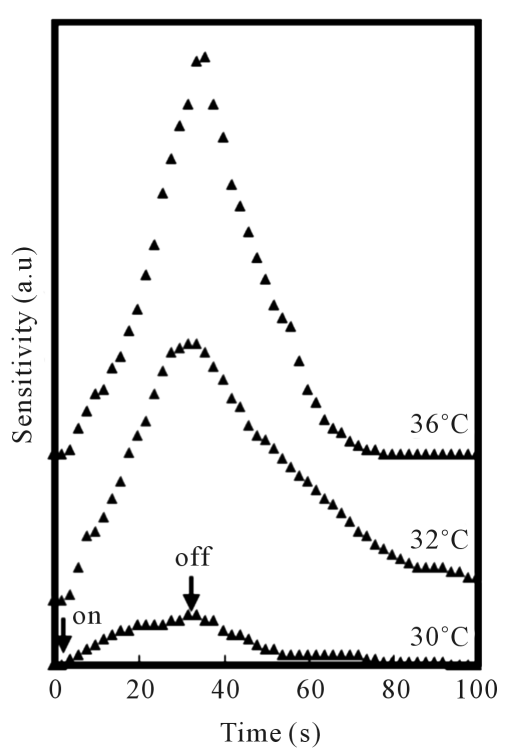

(b)

Figure 5. Variation of (a) resistance and, (b) sensitivity of undoped $\mathrm{Cu}_{2} \mathrm{O}$ thin films due to the exposures of films to LP gas at a flow rate $0.005 \mathrm{ml} / \mathrm{s}$ at different temperatures.

$\mathrm{Cu}_{2} \mathrm{O}$ films yielding two peaks in the magnitude of sensitivity vs. time graph. Figure 6(a) and Figure 6(b) show the resistance and the magnitude of sensitivity variations at temperatures of $30^{\circ} \mathrm{C}, 35^{\circ} \mathrm{C}, 39^{\circ} \mathrm{C}, 40^{\circ} \mathrm{C}$ and $42^{\circ} \mathrm{C}$ obtained for chlorine doped $\mathrm{Cu}_{2} \mathrm{O}$ thin films upon exposure to the $\mathrm{LP}$ gas. In contrast to the response given by undoped $\mathrm{Cu}_{2} \mathrm{O}$ samples in which the variation of resistance gives rise to only a single peak, it can be seen that at temperatures of $30^{\circ} \mathrm{C}, 35^{\circ} \mathrm{C}$ and $39^{\circ} \mathrm{C}$, there are two responses, with the first peak appearing around $10 \mathrm{~s}$ and the second peak appearing around $30 \mathrm{~s}$, before the gas is made to stop flowing. The second peak in the sensitivity vs. time graph in the Figure 6(b) is comparable to the peaks seen when undoped $\mathrm{Cu}_{2} \mathrm{O}$ was used as shown in Figure 5(b).

Therefore, the first peak appears to have arisen due to the presence of chloride ions in the doped $\mathrm{Cu}_{2} \mathrm{O}$ films. Thus for the sake of clarity, the first peak is termed as the chlorine peak whereas the second peak is termed as the $\mathrm{Cu}_{2} \mathrm{O}$ peak. Furthermore, it can be seen that the chlorine peak reduces its intensity with increasing temperature disappearing completely at $42^{\circ} \mathrm{C}$ whereas the intensity of the $\mathrm{Cu}_{2} \mathrm{O}$ peak continues to increase.

This behavior can be understood in the following manner. Overall reduction of the resistance of the chlorine doped thin films measured under atmospheric conditions is attributed to the increase of electron density in the conduction band of the $\mathrm{Cu}_{2} \mathrm{O}$ thin film which occurs due to the electrons coming from the donor impurity levels. Thus the doping concentration controls the overall resistivity of the $\mathrm{Cu}_{2} \mathrm{O}$ film. However, when the films are exposed to the LP gas, due to the formation of electrostatic interactions between induced dipoles of LP gas molecules with the chloride ions in the film, the electron pumping process to the conduction band is retarded causing the resistance to increase initially. When the interaction with chloride ions reaches its saturation, the adsorbed oxygen in the film starts to react with the LP gas molecules as stated above according to the Equation (2) causing the resistance to decrease similar to the undoped $\mathrm{Cu}_{2} \mathrm{O}$ films until the gas flow is stopped. It can also be seen that compared to the undoped $\mathrm{Cu}_{2} \mathrm{O}$ films, the initial response to the $\mathrm{LP}$ gas arising from the chlorine doped $\mathrm{Cu}_{2} \mathrm{O}$ films is quicker.

When the chlorine doped thin films are exposed to LP gas at temperatures $>42^{\circ} \mathrm{C}$, the absence of the chlorine peak indicates that the gas is not responsive to chloride ions present in the film sample due to the weakening of the dipole interactions between the LP gas molecules and the chlorides at higher temperature. Thus the contribution to the sensing behavior arises only from the adsorbed $\mathrm{O}_{2}^{-}$on the surface of the film. Therefore, the chlorine doped $\mathrm{Cu}_{2} \mathrm{O}$ films show a response similar to the undoped $\mathrm{Cu}_{2} \mathrm{O}$ thin film samples however, showing contrasting differences in the peak sensitivities measured as a function of temperature. Figure 7(a) and Figure 7(b) show the sensitivity measurements made of the chlorine doped samples for corresponding resistance variation 


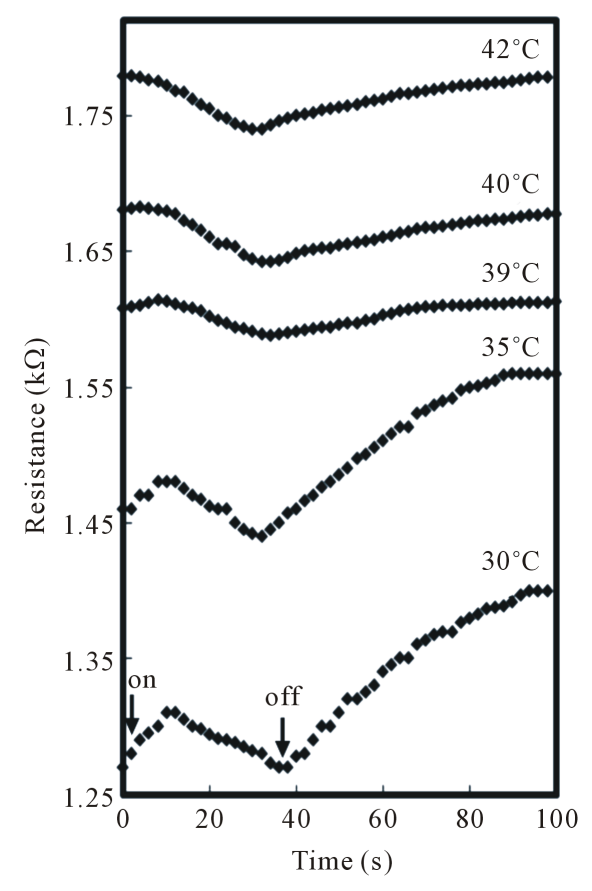

(a)

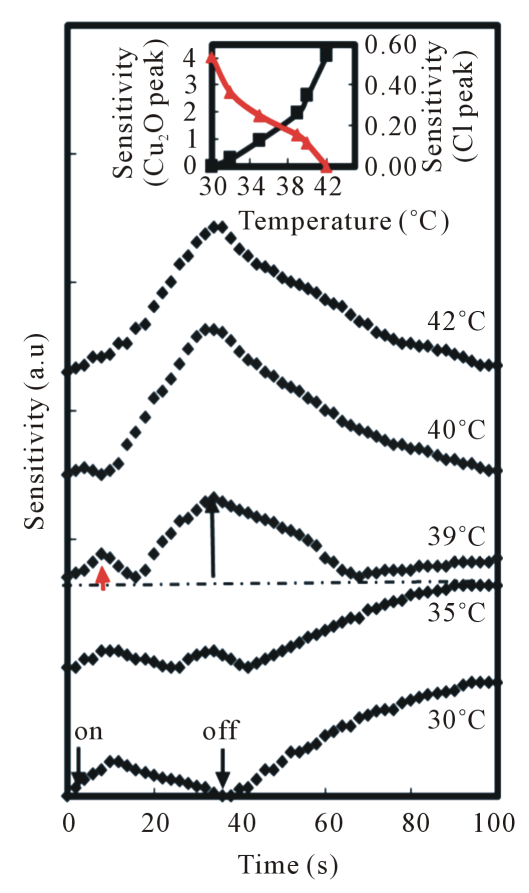

(b)

Figure 6. Temperature dependent variation of (a) resistance and (b) sensitivity of chlorine doped $\mathrm{Cu}_{2} \mathrm{O}$ thin films deposited in electrolyte solution with $0.02 \mathrm{M} \mathrm{CuCl}_{2}$ when films were exposed to LP gas at a flow rate of $0.005 \mathrm{ml} / \mathrm{s}$. (Inset: $\Delta$ variation of maximum sensitivity in the chlorine peak, and variation of maximum sensitivity in the $\mathrm{Cu}_{2} \mathrm{O}$ peak of the chlorine doped $\mathrm{Cu}_{2} \mathrm{O}$ thin films with the temperature).

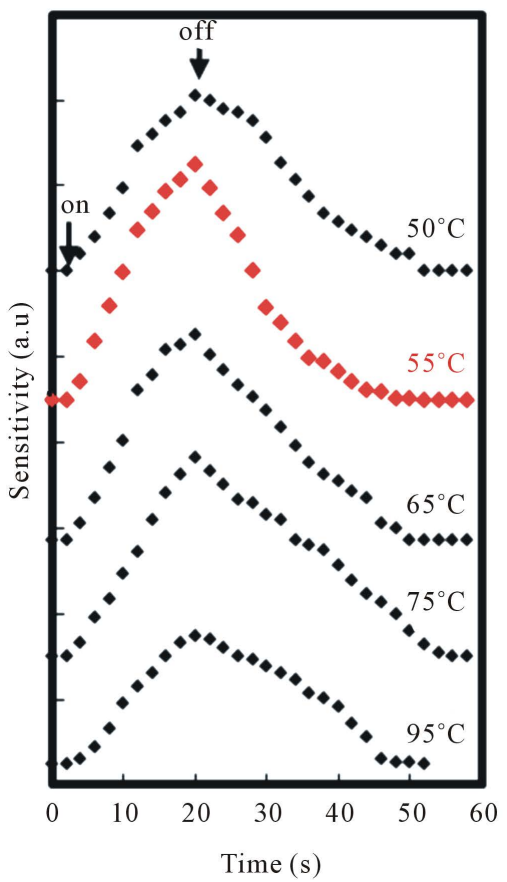

(a)

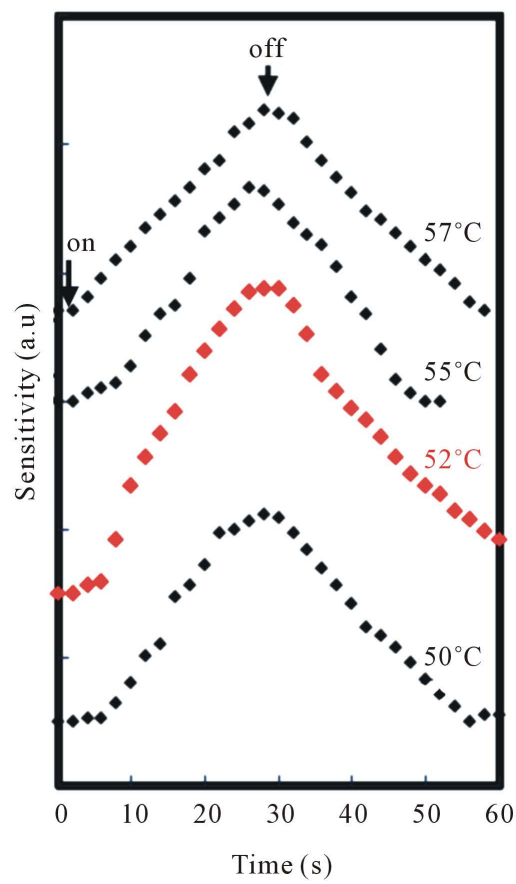

(b)

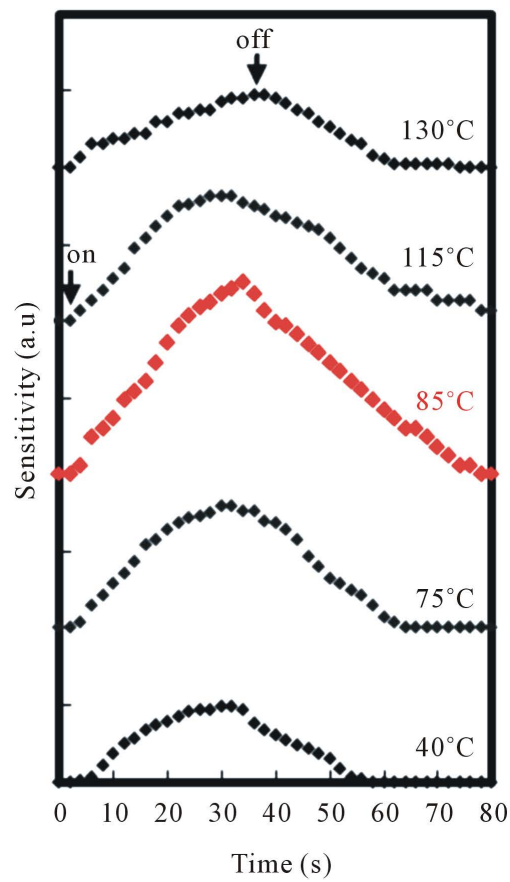

(c)

Figure 7. Variation of sensitivity of (a) chlorine doped $\mathrm{Cu}_{2} \mathrm{O}$ thin films at the high temperatures, (b) chlorine doped $\mathrm{Cu}_{2} \mathrm{O}$ thin films at temperatures around $55^{\circ} \mathrm{C}$ and, (c) undoped $\mathrm{Cu}_{2} \mathrm{O}$ thin films at the different temperatures due to the exposure of films to LP gas. (Highlighted in red are the variations of sensitivity that yields the maximum peak sensitivity.) 
when the LP gas was sent changing the film temperature in the range from $50^{\circ} \mathrm{C}-95^{\circ} \mathrm{C}$. Measurements showed that the intensity of the $\mathrm{Cu}_{2} \mathrm{O}$ sensitivity peak of the chlorine doped sample increased with temperature up to about $55^{\circ} \mathrm{C}$ and decreased with further increase in temperature. By varying the temperature around $55^{\circ} \mathrm{C}$, it was found that the maximum sensitivity was resulted in at $52^{\circ} \mathrm{C}$. In contrast, the undoped $\mathrm{Cu}_{2} \mathrm{O}$ films showed the maximum sensitivity around $85^{\circ} \mathrm{C}$ as shown by the Figure 7 (c).

Above behavior was repeatedly observed when both doped and undoped $\mathrm{Cu}_{2} \mathrm{O}$ thin film samples were exposed to the LP gas indicating that doping affects the overall gas sensing behavior of the films also.

\section{Conclusion}

In conclusion, it can be clearly seen that the chlorine doping has altered the gas sensing behavior of n-type $\mathrm{Cu}_{2} \mathrm{O}$ thin films significantly. While chlorine doping causes the resistance of $\mathrm{Cu}_{2} \mathrm{O}$ films to go down drastically, the presence of chloride ions in the film has resulted in an additional sensitivity peak that exists closer to the room temperature. It can be interpreted that the doping has caused LP gas molecules to interact initially with more active chloride ions providing a faster positive response, i.e. $\Delta R\left(=R_{\mathrm{LPG}}-R_{\text {air }}\right)>0$ and then with the $\mathrm{O}_{2}^{-}$ions on the $\mathrm{Cu}_{2} \mathrm{O}$ film providing a negative response, i.e. $\Delta R<0$ as in the case of undoped $\mathrm{Cu}_{2} \mathrm{O}$ films. It can also be seen that the maximum sensitivity of chlorine doped thin films to the LP gas occurs at a lower temperature compared to the undoped $\mathrm{Cu}_{2} \mathrm{O}$ films.

\section{Acknowledgements}

University Grant Commission of Sri Lanka is gratefully acknowledged for financial assistance provided through the research grant UGC/ICD/RG 2011. KNDB is thankful to the Open University of Sri Lanka, for granting leave to carry out this research study.

\section{References}

[1] Seiyama, T., Kato, A., Fujiishi, K. and Nagatani, M. (1962) A New Detector for Gaseous Components Using Semiconductive Thin Films. Analytical Chemistry, 34, 1502-1503. http://dx.doi.org/10.1021/ac60191a001

[2] Parmar, M. and Rajanna, K. (2011) Copper (II) Oxide Thin Film for Methanol and Ethanol Sensing. International Journal on Smart Sensing and Intelligent Systems, 4, 710-725.

[3] Yamazoe, N., Sakai, G. and Shimanoe, K. (2003) Oxide Semiconductor Gas Sensors. Catalysis Surveys from Asia, 7, 63-73. http://dx.doi.org/10.1023/A:1023436725457

[4] Ahalapitiya, H.J., Samarasekara, P. and Kun, G. (2009) Methane Gas Sensors Application of Cuprous Oxide Synthesized by Thermal Oxidation. Physica Status Solidi (a), 206, 332-337. http://dx.doi.org/10.1002/pssa.200824126

[5] Shishiyanu, T.S. and Lupan, O.I. (2006) Novel $\mathrm{NO}_{2}$ Gas Sensor Based on $\mathrm{Cu}_{2} \mathrm{O}$ Thin Films. Sensors and Actuators B: Chemical, 113, 468-476. http://dx.doi.org/10.1016/j.snb.2005.03.061

[6] Dhawle, D.S., et al. (2009) Liqueified Petoleum Gas (LPG) Sensing Perfomance of Electron Beam Irradiated Chemically Deposited $\mathrm{Ti}_{2} \mathrm{O}$ Thin Film. Sensors and Actuators B: Chemical, 141, 58-64. http://dx.doi.org/10.1016/j.snb.2009.06.025

[7] Shukla, T. (2012) Synthesis of Tin Oxide Thick Film and Its Investigation as a LPG Sensor at Room Temperature. Journal of Sensor Technology, 2, 102-108. http://dx.doi.org/10.4236/jst.2012.23015

[8] Siripala, W. and Kumara, K.P. (1989) A Photo Electrochemical Investigation of n- and p-Type Semiconducting Behavior of Copper Oxide Films. Semiconductor Science and Technology, 4, 465. http://dx.doi.org/10.1088/0268-1242/4/6/007

[9] Jayathilaka, K.M.D.C., Siripala, W. and Jayanetti, J.K.D.S. (2013) Efficiency Improvement of Cuprous Oxide Based Cl Doping. Proceedings of the International Conference (Solar Asia), Kuala Lumpur, 91-96.

[10] Bandara, K.N.D., Jayathilaka, K.M.D.C., Siripala, W. and Jayanetti, J.K.D.S. (2012) Electrodeposited Nano Crystalline $\mathrm{Cu}_{2} \mathrm{O}$ Thin Films for Gas Sensing Applications. Proceedings of the 68th Technical Sessions, Sri Lanka Association for the Advancement of Science (SLAAS), 56.

[11] Han, X.F. (2011) Electrochemical n-Type Doping in Metal Oxides and Its Application in Photovoltaic. Ph.D. Thesis, University of Texas at Arlington, Arlington, 32-33. 
Scientific Research Publishing (SCIRP) is one of the largest Open Access journal publishers. It is currently publishing more than 200 open access, online, peer-reviewed journals covering a wide range of academic disciplines. SCIRP serves the worldwide academic communities and contributes to the progress and application of science with its publication.

Other selected journals from SCIRP are listed as below. Submit your manuscript to us via either submit@scirp.org or Online Submission Portal.
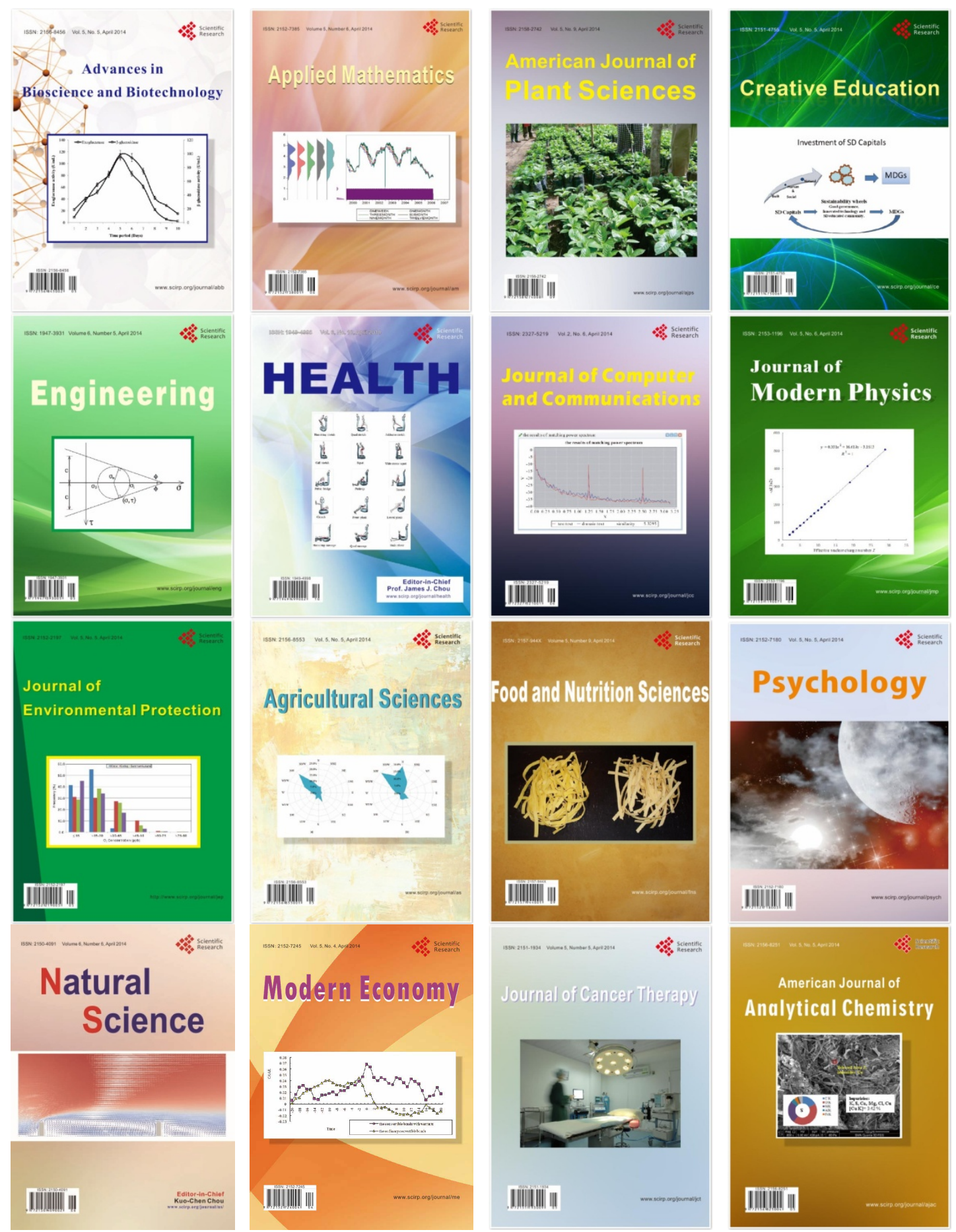